\title{
Loja como icono en las artes vivas, sobres sus potencialidades y posibilidades para el festival internacional
}

\section{Loja as an icon in the living arts, its potential and possibilities for the international festival}

Burneo Villamagua Jeamil S., Mgs.

Universidad Internacional del Ecuador, Ecuador

Autor para correspondencia: jeburneosa@internacional.edu.ec

Fecha de recepción: 30 de Agosto de 2016 - Fecha de aceptación: 01 de Noviembre de 2016

\section{Resumen}

El presente trabajo ofrece una visión actual respecto al desarrollo de la cultura lojana, de manera específica nos plantea un análisis del influjo que se genera con la realización del "Primer Festival Internacional de Artes Vivas, Loja 2016". Partiendo de la tradicional concepción de la ciudad de Loja como epicentro de algunas manifestaciones artísticas e identitarias en el país, se contrasta con criterios urbanos y productivos sobre la pertinencia de creación de un producto cultural que trascienda realización del festival, cuya sola identificación y funcionamiento es ya una aceptación tácita de algunos postulados mencionados en este documento. Al final se hace mención a algunos eventos similares que han sido tomados como referentes de la realización, haciendo hincapié en sus pros y sus contras, de igual manera se plantean algunas recomendaciones y conclusiones que se han generado desde la consulta directa en un grupo focal de interés definido para el efecto.

Palabras claves: artes escénicas; manifestaciones culturales; teatro; turismo cultural; tradición

\begin{abstract}
This paper provides a current view on the development of the Loja's culture, specifically presents us with an analysis of the influence that is generated with the completion of the "First International Festival of Living Arts, Loja 2016". Starting from the traditional conception of the city of Loja as the epicenter of some artistic and identity demonstrations in the country, it is contrasted with urban and production criteria on the relevance of creating a cultural product that transcends realization of the festival, whose only identification and operation is and a tacit acceptance of some postulates mentioned herein. At the end it referred to some similar events that have been taken concerning the realization, emphasizing their pros and cons, likewise raised some recommendations and conclusions that have been generated from direct consultation in a focus group defined for this purpose interest.
\end{abstract}

Key words: performing arts; cultural events; theatre; tourism cultural; tradition 


\section{Introducción}

Desde el año 2014, se plantea desde sectores gubernamentales y desde la sociedad civil, el interés en desarrollar un festival internacional de teatro en Loja, manifestando como objetivo "rescatar el título que siempre tuvo y mereció la ciudad de Loja como capital cultural de Ecuador" (Comunicación, 2015), en dicho cometido intervienen algunos elementos, como la construcción de un moderno teatro con aforo aproximado de un millar de personas. Las características de dicho evento en primera instancia se van determinando por algunos parámetros consciente o inconscientemente adoptados por los organizadores, uno de ellos se destaca precisamente en la búsqueda de no restringir el desarrollo de la manifestación cultural a la mencionada infraestructura arquitectónica, sino de ampliarlo hacia la apropiación como manifestaciones públicas en las plazas de la ciudad de Loja, y además ampliar su visión específicamente teatral, a una categoría que amplía su cobertura: las artes vivas. De esta característica y de la afirmación de las autoridades mentalizadoras es que se convierte en un referente destacado en la planificación del naciente ícono cultural del país, el festival francés de Aviñón, el cual en este artículo será abordado y estudiado correlacionándolo con las características propias de entorno local; para los lojanos, la connotación mediática asociada con este reconocimiento contemporáneo hacia la tradición cultural y artística, varias veces mencionada en diferentes foros que tiene como parangón necesario la pretérita identificación institucional del máximo organismo cultural en la "casa de la Cultura Benjamín Carrión” con el nombre del insigne lojano; se convierte en un reto que dicho esfuerzo se aproveche en la magnitud adecuada y se integren diversos actores con miras a brindarle sostenibilidad y a erigir una imagen correcta del ícono cultural. Abordaremos por lo tanto seis apartados con ese cometido, teniendo especial interés en aportar algunas ideas y recomendaciones para la implementación del evento mencionado, y cuya fecha de realización en opera prima se ha definido para mediados del mes de noviembre del presente año, el 1er Festival internacional de artes vivas Loja 2016.

\section{Ciudad contenedor de creatividad, cultura como factor de desarrollo local y proyección exterior de la ciudad}

La ciudad de Loja, se encuentra ubicada en la zona sur del Ecuador, al ser una ciudad fronteriza muestra una manifestación cultural suigéneris enfocada el ser humano con sus tradiciones. Los habitantes de la ciudad reciben a turistas con la hospitalidad que los caracteriza, esta sale a flote junto con la creación artística musical, la misma que ha sobresalido nacional e internacionalmente, mostrando una ciudad para descubrir y explorar. (Espinoza., 2012)

Loja es conocida como una ciudad de destacada cultura y tradiciones en diferentes ámbitos como música, teatro, danza, gastronomía y museos. Es reconocida como la capital musical del Ecuador por el hecho de formar los mejores músicos del país, por la eclosión de manera periódica en la historia de compositores, intérpretes y expositores de diversos géneros musicales que incluyen música popular, académica, contemporánea, de solistas y de agrupaciones; lo cual de igual manera ha generado algunos mitos, pues generalmente esta autocrítica es esbozada por algunos sectores culturales, aunque es notorio que las nuevas generaciones de músicos en los últimos años están refrendando los laureles que críticamente se los endosa exclusivamente a un "pasado glorioso". 
La cultura y sus manifestaciones deben trascender el romanticismo de dicho pasado y posicionarlo el presente como cualidad para producir cultura diversa y vanguardista, desde esta perspectiva contemporánea, creemos que la clave de la cultura se sitúa en las ciudades, este contenedor territorial que en su interior define como su materia prima a la creatividad, la capacidad de innovar, transformar y crear otra realidad. Los conceptos modernos de creatividad vinculan patrimonio local, pasado y actual, abarcan la ciencia, la moda, la tecnología, la gastronomía; este patrimonio todavía no se ha musealizado. A Loja, por ejemplo, como a otras ciudades del Ecuador, actualmente llegan, por fuera de una corriente globalizadora mediática, diversos ejecutores del arte popular, el llamado juglar; que es un artista ambulante, brinda arte callejero al transeúnte, para ellos el atractivo de Loja tiene singularidad en nuestro país siendo notoria su inclinación a visitarla. En esta convivencia de lo antiguo con lo moderno, es importante que se haya incluido en la programación y la personalidad del Festival de Artes Vivas de Loja, una vocación eminentemente popular de este arte el cual se lo realizará en el espacio público, bosquejando en este punto la primera relación de reciprocidad artística, dar para recibir, y creemos que en la exposición pública de Loja, se puede ganar mucho con el cultivo de la academia especializada en las Artes, una importación proactiva.

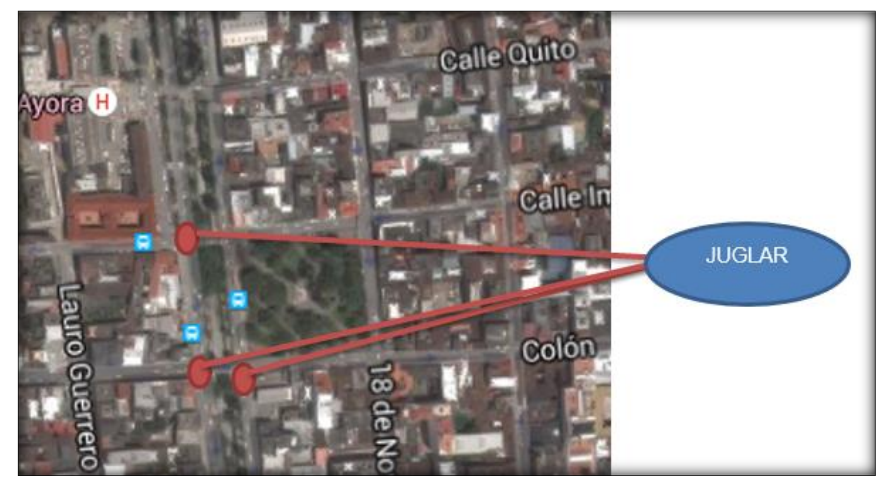

Ilustración 1. Los juglares se encuentran ubicados en la av. Universitaria y Colón, en la av. universitaria e Imbabura.

Elaboraron: Estudiantes de Arquitectura UIDE Loja

La cultura de la ciudad debe considerar por lo tanto la participación como medio y como fin. Hablamos de creatividad y de participación en la vida cultural como un elemento constitutivo del desarrollo sostenible de una comunidad, casi una condición sine qua non, para influir en distintos grados en las esferas del empleo, de la educación, de las artes, así como de enriquecer sus horizontes identitarios.

La cultura es un gran factor de desarrollo y reconocido como un componente importante de crecimiento pues "antes de que la economía se considerara como ciencia, hecho atribuido a los economistas clásicos, ya se buscaba el crecimiento económico, entendido éste como el aumento de la riqueza". (Ignacio Amate Fortes, 2011). Creemos que el ámbito artístico cultural debe construir su propia estructura productiva y de distribución, además de redefinir en algunos casos la acción pública en materia cultural de los gobiernos locales, los cuales deben tener como objetivo la dinamización de iniciativas culturales avanzadas, complementariamente con otros recursos endógenos. "El reto del gobierno local está en compaginar crecimiento económico, capacidad emprendedora, innovación, creatividad y formación con la cohesión social y el 
bienestar colectivo de la vecindad, desde la seguridad de que no hay soluciones generales para todos los contextos y sí consideraciones de las especificidades locales como marco de respuesta, ahora sí, a los desafíos generales.” (Casto, S. Ã.,2002)

\section{El desafío que representan las artes escénicas como dinamizador de desarrollo de loja}

En primera instancia, la idea de la implementación de un evento de la magnitud propuesta sugería la preponderancia de una disciplina como el Teatro, paulatinamente hemos observado que el ámbito se lo amplió hacia las artes escénicas y finalmente a las "artes vivas", posiblemente como búsqueda de globalidad e inclusión en un producto cultural que genere un ícono y que posicione a la ciudad de Loja como un destino específico contemporáneo. Se entiende por artes escénicas al estudio y la práctica de toda forma de expresión que requiera de una representación, incluyendo la organización espacial y el espectáculo, pero también en cualquier espacio arquitectónico o urbanístico construido para realizar cualquier tipo de espectáculo en vivo, como ocurre con los espectáculos ambulantes (como el circo, el guiñol, los tradicionales cómicos de la legua y comedia del arte o el actual teatro callejero) siendo la forma de estas artes efímeras y vivas, que requiere de un público para completar la comunicación. (Asuaga, 2005)

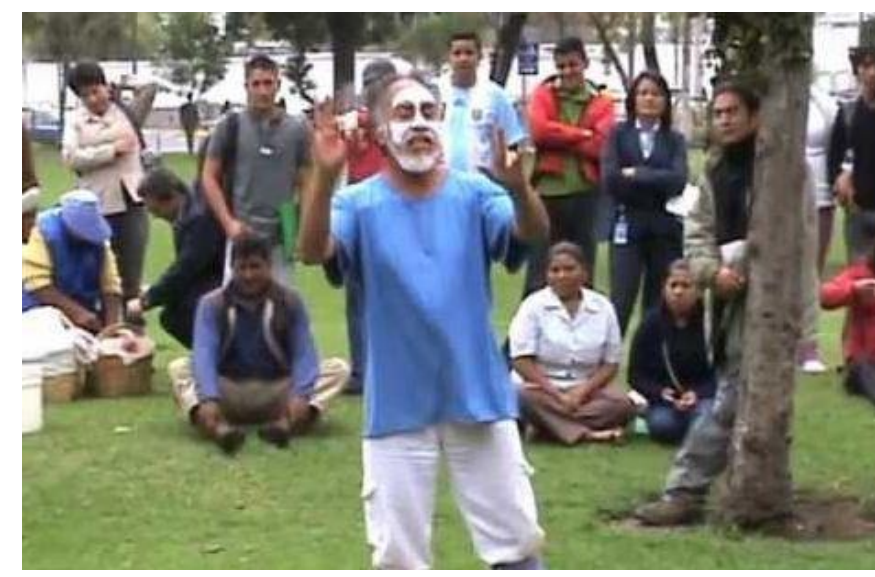

Ilustración 2: Carlos Michelena en el parque de El Ejido Quito representante del arte de la calle Fuente: David Almachi

Se entiende entonces como "arte escénica", a toda forma de expresión capaz de inscribirse en la escena: el teatro, la danza y la música que se lleve a cabo en algún tipo de espacio escénico, habitualmente en las salas de espectáculos, pero también en cualquier espacio arquitectónico o urbanístico construido especialmente o habilitado ocasionalmente para realizar cualquier tipo de espectáculos en vivo, las cuales expresan formas expresivas esencialmente sensoriales, las cuales desarrollan sus propuestas en relaciones concretas de espacio-tiempo, de forma directa con el público, estimulando la percepción sensorial del espectador. Cualquiera de las representaciones mencionadas implica que un director de escena debe coordinar elementos distintos que forman parte de un escenario: la iluminación, el decorado, el vestuario, la música, la ambientación, etc. 


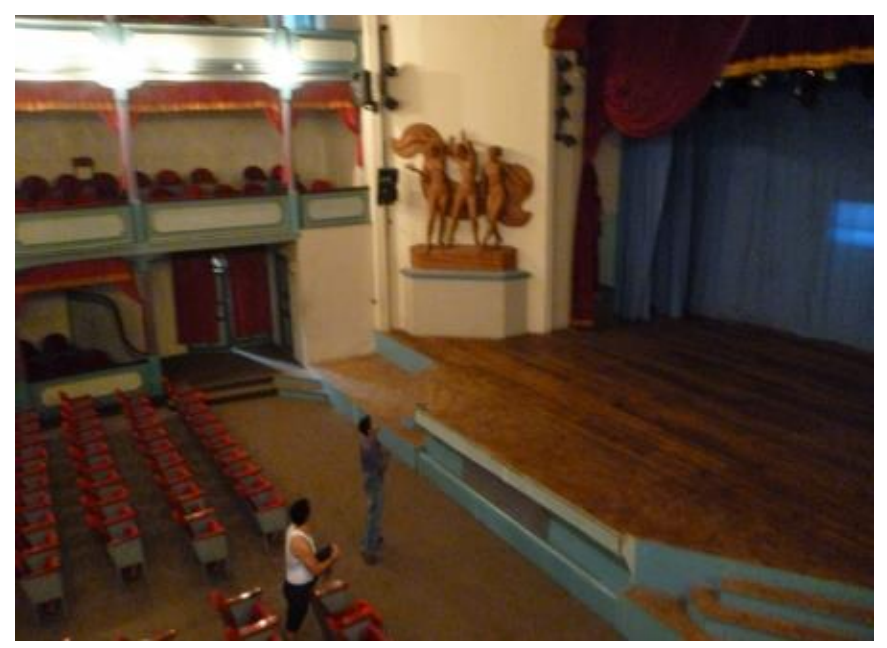

Ilustración 3 El Teatro Bolívar

Fuente: Estudiantes de Arquitectura UIDE Loja

El concepto de las "artes vivas" es una apuesta por la construcción del colectivo y de nuevas maneras de asociación para los procesos creativos independientes. Es una red que pone en contacto, permite conservar la autonomía artística y metodológica de cada creador y al mismo tiempo, suma esfuerzos. Supone un espacio permanente de intercambio y retroalimentación; trabajar nos permite visibilizar los múltiples espacios en los que tienen lugar los espacios del arte emergente e independiente. (Eloísa Jaramillo, 2012).

El proceso productivo del espectáculo en vivo tiene características propias que lo diferencian de los procesos que se dan en otros sectores de la economía. Se sostiene que las artes escénicas constituyen un bien o servicio que se agota en sí mismo, es decir, perece en el momento que se ofrece, ya que consumo y producción se realizan conjuntamente en el momento de la celebración. (Tandil).

En teoría, para poder realizar de manera satisfactoria este tipo de artes, se necesitan realizar algunas intervenciones que vinculen los intereses público y privado, que incluyan infraestructuras efectivamente adecuadas en un esfuerzo sistémico. Puntualizando en el caso de Loja, se integrarías dos componentes importantes: la entrega en el mes de Septiembre del Teatro Moderno bautizado como "Manuel benjamín Carrión” y por otro lado la revalidación de la infraestructura histórica relacionada, que incluye teatros, plazas, museos, centros culturales e inclusive el estadio de la ciudad, con el siguiente detalle facilitado por la instancia organizadora del evento: 


\begin{tabular}{|c|c|c|c|c|c|}
\hline \multicolumn{6}{|c|}{ Teatros y Cines de Loja } \\
\hline Nombre & Ubicación & Aforo & $\begin{array}{l}\text { Año de } \\
\text { Construcción }\end{array}$ & Pertenece a: & Evento \\
\hline $\begin{array}{l}\text { 1. Auditorio "Pablo } \\
\text { Palacio" }\end{array}$ & $\begin{array}{l}\text { Colón } 13-12 \text { Y } \\
\text { Bernardo Valdivieso }\end{array}$ & 300 Personas & - & Casa De La Cultura & $\begin{array}{l}\text { Se programaran varios espectáculos } \\
\text { durante el festival. }\end{array}$ \\
\hline $\begin{array}{l}\text { 2. Teatro } \\
\text { Universitario } \\
\text { "Simon Bolivar" }\end{array}$ & $\begin{array}{l}\text { Rocafuerte entre } \\
\text { Olmedo y Bernardo } \\
\text { Valdivieso }\end{array}$ & 400 Personas & 1913 & GAD Loja & $\begin{array}{l}\text { Se programaran varios eventos durante } \\
\text { el festival. }\end{array}$ \\
\hline 3. Teatro de Loja & $\begin{array}{l}\text { Av. Salvador } \\
\text { Bustamante Celi y } \\
\text { Agustin Carrión } \\
\text { Paredes }\end{array}$ & $\begin{array}{l}5000 \text { Personas } \\
\text { (Según Nota } \\
\text { Periodistica }{ }^{1} \text { ) }\end{array}$ & $\begin{array}{l}\text { Junio } 2013 \text { (En } \\
\text { construcción) }\end{array}$ & $\begin{array}{l}\text { Gobierno Provincial } \\
\text { de Loja }\end{array}$ & $\begin{array}{l}\text { Inauguración y clausura de varios } \\
\text { espectáculos escénicos durante el } \\
\text { festival, espectáculo cinematográfico y } \\
\text { exposición fotográfica internacional } \\
\text { sobre las artes escénicas. } \\
\text { Sala alterna (Espectáculos públicos para } \\
\text { jóvenes, talleres de danza y otros } \\
\text { géneros escénicos). }\end{array}$ \\
\hline $\begin{array}{l}\text { 4. Museo de la } \\
\text { Cultura Lojana }\end{array}$ & $\begin{array}{l}\text { Colón } 13-12 \text { Y } \\
\text { Bernardo Valdivieso } \\
\end{array}$ & - & - & GAD Loja & $\begin{array}{l}\text { Exposición museográfica, auditorio del } \\
\text { museo y una muestra de video danza. }\end{array}$ \\
\hline $\begin{array}{l}\text { 5. Plazas y } \\
\text { Espacios } \\
\text { Públicos }\end{array}$ & $\begin{array}{l}\text { San Sebastián } \\
\text { Santo Domingo } \\
\text { La Catedral } \\
\text { Plaza de la } \\
\text { Independencia Simón } \\
\text { Bolivar }\end{array}$ & - & - & GAD Loja & $\begin{array}{l}\text { Se harán obras escénicas de pequeño } \\
\text { formato, las calles alteraran una muestra } \\
\text { fotográfica y un ambicioso proyecto de } \\
\text { oralidad contemporánea. }\end{array}$ \\
\hline $\begin{array}{l}\text { 6. Centro de } \\
\text { Convenciones } \\
\text { UTPL }\end{array}$ & $\begin{array}{l}\text { Campus UTPL (San } \\
\text { Cayetano Alto) }\end{array}$ & 800 Personas & 2005 & UTPL & $\begin{array}{l}\text { Encuentro nacional de artes escénicas } \\
\text { que incluirá actos académicos. }\end{array}$ \\
\hline $\begin{array}{l}\text { 7. Estadio Reina del } \\
\text { Cisne }\end{array}$ & $\begin{array}{l}\text { Av. Emiliano Ortega y } \\
\text { Azuay }\end{array}$ & 14.900 Personas & 1980 & GAD Loja & $\begin{array}{l}\text { Festival musical con bandas alternativas } \\
\text { contemporáneas. }\end{array}$ \\
\hline $\begin{array}{l}\text { 8. Centro Cultural } \\
\text { Pio Jaramillo } \\
\text { Alvarado }\end{array}$ & $\begin{array}{l}\text { Vicente Rocafuerte y } \\
\text { Bernardo Valdivieso }\end{array}$ & 500 personas & 2000 & Municipio De Loja & $\begin{array}{l}\text { Se programaran varios eventos durante } \\
\text { el festival. }\end{array}$ \\
\hline
\end{tabular}

Se deben considerar algunos aspectos adicionales, en la planificación sistémica de este producto cultural, por ejemplo la implementación adecuada de su señalética, al igual de la provisión de parqueaderos fuera de la red de comunicación de plazas para una mejor accesibilidad, identificar las iniciativas complementarias favorables en redes de distribución de artesanías, souvenirs, hospedaje, alimentación y recursos endógenos propios de Loja, algunos de los cuales precisamente en la actualidad se encuentran mutando con la construcción del proyecto de regeneración su casco histórico y algunos sectores aledaños . Es eminentemente necesario que además de las alianzas público-privadas lógicas y ya establecidas, se amplíen acuerdos con asociaciones artísticas y grupos locales, con el objetivo de generar producción, pasar de ser exclusivamente receptores a creadores, esta es la visión de los entendidos en estas disciplinas, quienes además plantean la noción del teatro público (como intangible) con vocación de servicio, que asuma una dosis de riesgo y la heterogeneidad de públicos, que promocione el teatro de base, la diversidad de géneros, en otras palabras democratizar su acceso a la ciudadanía, considerando como un público a los niños en un proceso de siembra que lo perciban como una actividad cotidiana. El arte en este sentido se considera como una "plataforma intergeneracional de encuentro, expresión, lúdica y socialmente terapéutica, se ha definido precisamente que las diversas modalidades de aplicación de estrategias teatrales y escenográficas, sin duda, revierten cultural y recreativamente en la comunidad, entre otras plusvalías sociales." (Pose, H. M.,2008)

\section{La cultura como factor de desarrollo local y proyección exterior de la ciudad}

Las ciudades, citando a Héctor Manuel Pose Porto, son consideradas como contenedores culturales, los cuales deben cumplir algunos requerimientos para ser acogedoras al teatro y afines: han de poseer una programación estable con un criterio de calidad y no sólo de rentabilidad económica, pues la acción pública teatral debe tener en cuenta que tratamos de 
democratizar el acceso a la ciudadanía a las artes escénicas, por otro lado se considera necesaria la coordinación y el trabajo en red con las parroquias periféricas de Loja.

Uno de nuestros valores diferenciadores, y en la lógica de empresas culturales, definitivamente es el tamaño de la ciudad, pues actualmente vivimos inmersos en una tendencia de retorno hacia lo local, y en esta revalorización de lo territorial, son las ciudades de tamaño medio o intermedias las que parecen reunir mejores posibilidades. En nuestro caso además incluiríamos a estos escenarios, una posición privilegiada en una lógica regional, expuesta de manera insistente en diversos ámbitos y que podría posicionar al hito cultural concebido en el proyecto cultural, como un integrador temático transfronterizo con el norte del Perú y como un elemento de articulación cultural de la región Sur de nuestro país, que además tiene como reto la concreción de la vía interoceánica.

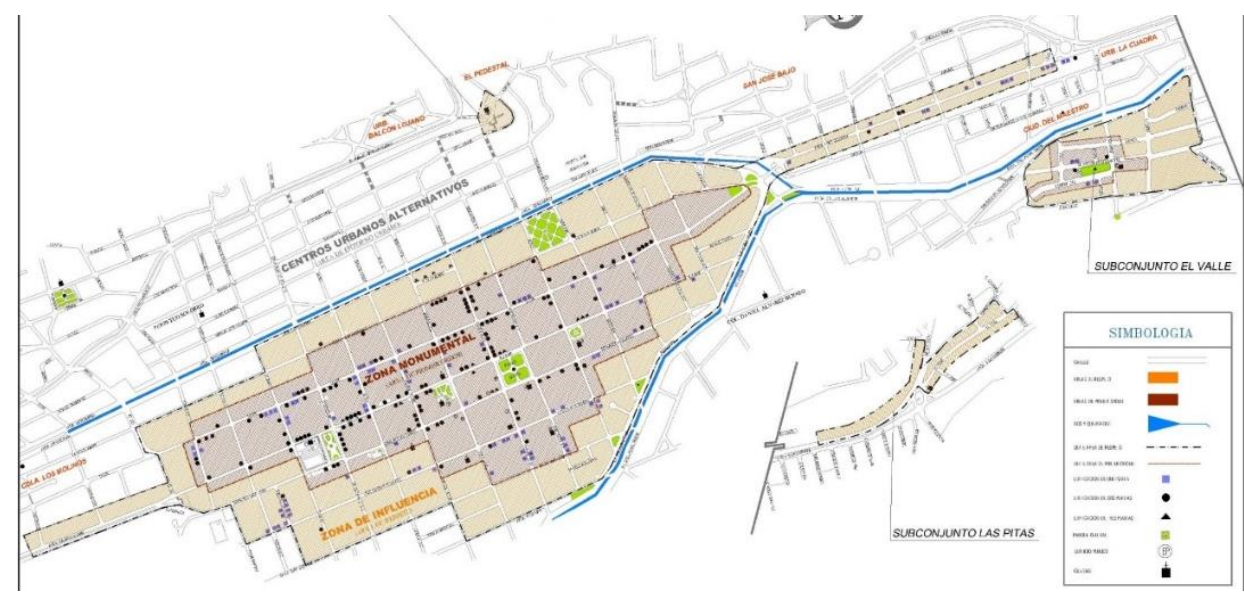

Ilustración 4: Delimitación del centro histórico de Loja

Fuente: Prospectiva y proyectos de del municipio de Loja.

Estas urbes, en su acción cultural, deben enfocar su oferta, además de cara a sus habitantes, con base en el atractivo exterior que busquen, en su entorno inmediato. La ciudadanía se mueve según las ofertas que recibe, obviando a menudo los límites administrativos que señalan los municipios.

Si hablamos de indicadores, deberíamos mencionar que el desarrollo cultural de una comunidad debería basarse en parámetros de cultura ecocentrada (equilibrio en la relación hombre naturaleza) que incidan en la formación, en el fomento de la participación, en la identidad local, en la capacidad crítica de la ciudadanía y de sus agentes, en la voluntad de innovación y en la disponibilidad de apertura hacia la modernidad (Pose, H. M.,2008).

Podemos considerar a este entorno como un laboratorio propicio para el reciclaje urbanístico de la ciudad, pues como veremos buena parte de la oferta cultural del festival internacional de artes vivas Loja 2016, considera el emplazamiento de algunas de sus obras en espacios públicos, lo que la jerga especializada considera el "Festival en off", la lógica de relacionamiento de dichos escenarios podría generar algunas posibilidades de circuitos como el que considera a la calle Bolívar como principal eje articulador de ellos, vinculándolos a través de arterias secundarias en el agrupamiento más importante emplazado en el Centro Histórico de la ciudad. 


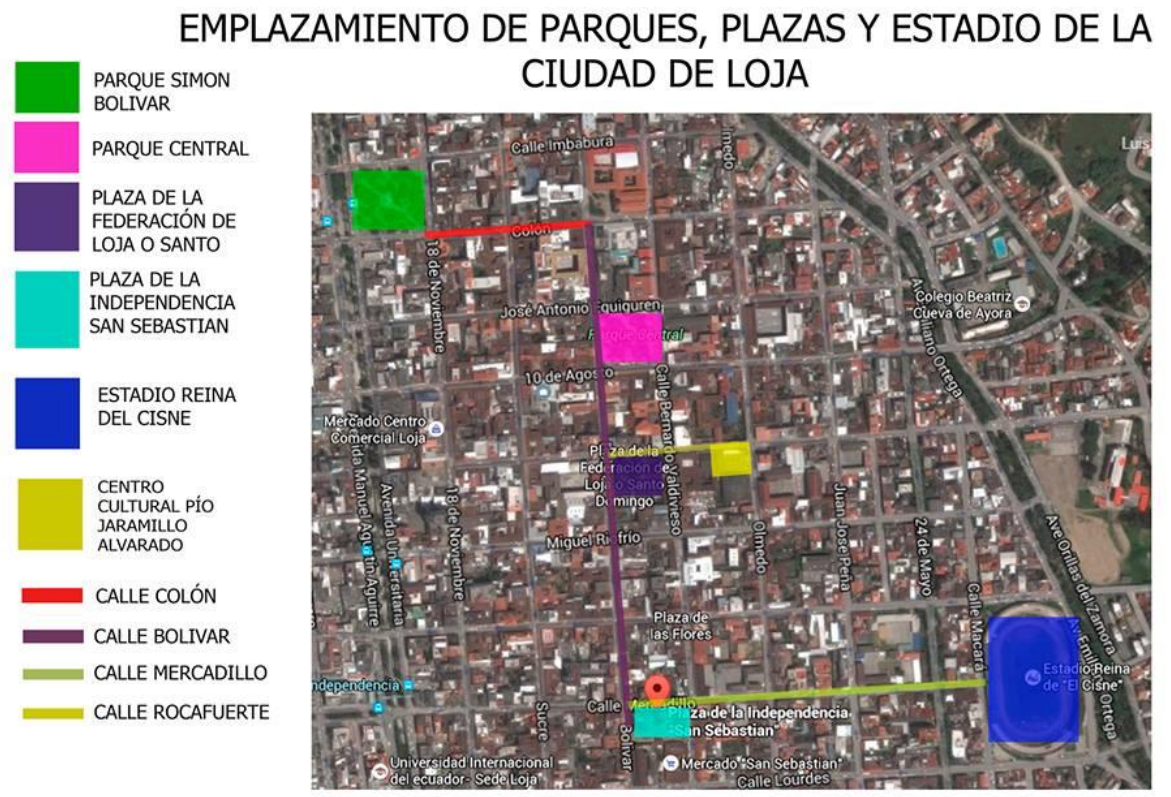

Ilustración 1 Emplazamiento de parques, plazas y del estadio de la ciudad de Loja Fuente: Autores

Un circuito complementario integraría el moderno teatro de Loja (en construcción), el cual es el escenario principal del festival, con el parque recreacional temático de "Jipiro", el conservatorio de música "Salvador Bustamente Celi", el parque "El Valle" y finalmente conectándolo desde la Av. Salvador Bustamente Celi, Av. Santiago de las montañas, calle Zoilo Rodríguez, finalmente por la prolongación de la calle 24 de mayo hacia el centro histórico de Loja.

\section{Los festivales como iconos para las ciudades}

Para el caso de Loja, la interrogante, es ¿de qué manera conseguir la generación de un ícono convocante al orbe, que potencie las características tradicionales de atractor cultural de nuestra ciudad y provincia hacia un producto reeditado que genere un posicionamiento externo adecuado? Vemos que un modo de vincular el patrimonio endógeno con el atractivo y la proyección exterior de la ciudad son los derivados de iniciativas de carácter proteccionista, las de naturaleza artística y creativa y las de potenciación de las festividades locales singulares. Tales como en España como los Festivales de Cine de San Sebastián, de Jazz de Vitoria-Gasteiz, el Festival Mozart de A Coruña, el Are-More en Vigo o, por citar casos que tienen lugar en otras ciudades europeas, el Festival Internacional de Teatro de Avignon e incluso el afamado Festival de Edimburgo pretenden, con seguridad, acercar las diversas artes a la ciudadanía local, pero también, generar focos de atracción que hagan de las respectivas ciudades, unos destinos anuales inexcusables para muchos aficionados en estos casos, al teatro, la danza, la música clásica, el canto o el cine. La pretensión consiste en convertir la ciudad en un sugestivo emisor de mensajes lúdicos y culturales, capaz de introducirse en lo posible en la denominada cultura universal. Esta intención no se consigue tan sólo con la organización de actos más o menos lúdico-culturales, sino, principalmente, con políticas que comprendan la articulación paralela de estructuras y de 
estrategias de apoyo a los creadores, que doten el territorio de infraestructuras de proximidad, que generen y participen en redes, implicando a las industrias culturales privadas y demás agentes sociales e instituciones en la tarea. Y recordando que para avanzar por esta senda, estimamos que los profesionales de la educación y de la cultura deben trabajar más estrechamente, buscando un compromiso mutuo entre acción cultural y educativa a nivel local (Pose, H. M., 2008). En el caso de Loja además conviven en la actualidad, nuevas formas de exposición y divulgación de la producción artística con énfasis en la música, pero además con singularidades propias como la oratoria, la danza, las bandas de pueblo en esfuerzos de posicionarlas como espectáculos sinfónicos, pues actualmente un indicador que evidencia el prestigio mencionado, lo constituyen la presencia de dos orquestas sinfónicas locales.

Queda también para la ciudadanía una visión proactiva de una urbe que tiene un tamaño adecuado para posicionarse como un referente de "calidad de vida" que ha sabido integrar algunas características sociológicas del lojano con la vida contemporánea como el esfuerzo de clasificación domiciliaria de la basura, su posterior reciclaje y reutilización, la vocación ambientalista, la innovación, el liderazgo de las universidades, el nivel de ruido generado por el tránsito vehicular notoriamente menor, entre otros, que generan actualmente un flujo turístico del norte del Perú bastante importante. Se podría hablar de un ícono, que en términos de turismo y flujo de divisas, dinamice la economía de la ciudad, como argumenta Flores Ruiz, llegando en una etapa de madurez del festival de Cine de Huelva en España, a contabilizar cerca de la mitad de afluencia de turismo vinculado con la convocatoria del evento:

\section{MOTIVOS DE ASISTENCIA A HUELVA}

\begin{tabular}{|l|c|c|}
\hline \multicolumn{1}{|c|}{ Motivos asistencia a Huelva } & Personas & Porcentaje \\
\hline Principal: el Festival & 1116,46 & 49,3 \\
\hline Uno de los motivos & 663,54 & 29,3 \\
\hline No ha influido el Festival & 409,90 & 18,1 \\
\hline Ns/Nc & 74,73 & 3,3 \\
\hline Total & $2.264,64$ & $\mathbf{1 0 0 , 0}$ \\
\hline
\end{tabular}

Cuadro 1. "Análisis de la afluencia turística a la ciudad de Huelva, España" Fuente: (Flores Ruiz, D.,2015) Sobre el festival de cine de Hueva.

Se puede entender estas características, expresando que el proceso de globalización también ha modificado el papel que tradicionalmente se venía reservando a las ciudades y a las administraciones locales, vemos como los municipios han pasado de ser meros gestores de servicios a liderar y promover iniciativas y proyectos. "Y es que las ciudades compiten en este nuevo universo económico global en el que las decisiones vinculadas al desarrollo económico y social se han deslocalizado. Las ciudades han de mostrar su rostro más amable, han de ser atractivas a residentes, visitantes e inversores, han de convertirse en espacios habitables y atractivos, han de crear un ambiente innovador que facilite la creatividad, estimule el espíritu emprendedor y permita la concertación de los distintos agentes sociales y económicos, han de estar conectadas con las redes mundiales, han de trabajar en áreas económicas con un mercado potencial suficiente y han de asumir la descentralización de responsabilidades que de facto han puesto en marcha los gobiernos regionales y/o nacionales. Sin duda, las ciudades han de redefinir sus objetivos y estrategias y en esa redefinición, que tiene por base la calidad y la excelencia, la cultura aporta valores de cohesión, sostenibilidad y desarrollo innegable, un nuevo rol de las ciudades en el que la cultura juega un nuevo papel mucho más central y decisivo. Los programas 
políticos de las ciudades más dinámicas e innovadoras van poniendo de relieve el nuevo papel de la cultura en la política local." (Casto, S. Ã.,2002).

"La política local que vienen impulsando las ciudades con el desarrollo de actividades en el marco de las artes escénicas, como la música, el teatro, los museos y en el cine son en la actualidad no sólo un factor de atracción del turismo urbano sino una demanda de calidad de vida que tiene una gran capacidad para generar empleo directo y desarrollo económico local" (De Elizagarate, V. , 2003).

En los referentes consultados, especialmente europeos, vemos que la demanda de cultura ha impulsado el desarrollo de una red de infraestructuras culturales con gran impacto en la regeneración urbana de la ciudad, que crean centralidad y son promotores del desarrollo económico por el impacto de las inversiones y el gasto generado por los visitantes. Estas infraestructuras que potencian el turismo de festivales constituyen un buen ejemplo de oferta turística complementaria, la cual, en algunos casos, puede llegar a convertirse en el principal motivo de la visita al destino turístico, tal y como es el caso del Festival Internacional de Cine de San Sebastián (País Vasco, España).

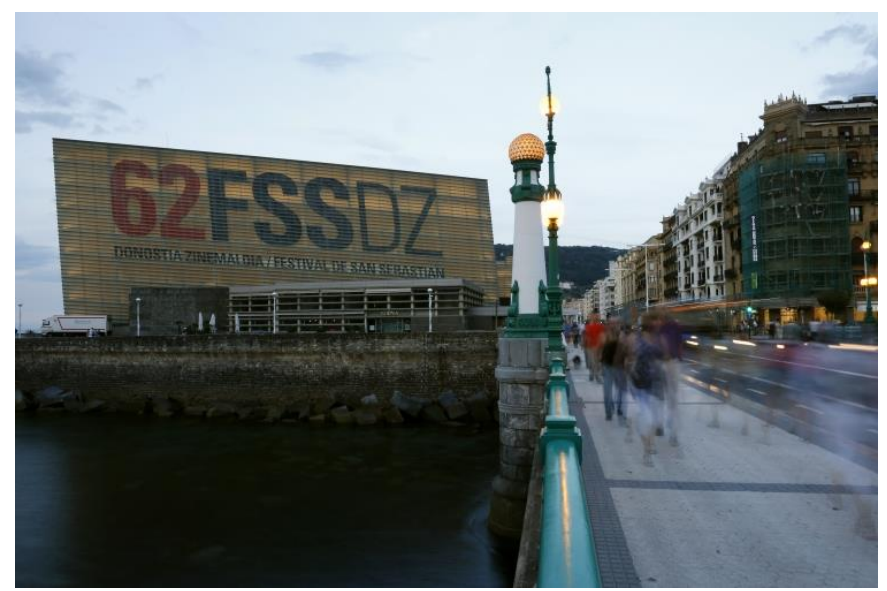

Ilustración 4. San Sebastián, Donostia, País Vasco, España. Fuente: Divulgación del evento.

\section{El festival de avigñon, ¿un referente válido a aplicar?}

Estableciendo algunas nociones generales a cerca de este renombrado festival de teatro, que fue considerado el referente más importante para la implementación del Festival de Loja, podríamos sacar algunas conclusiones al final que sirvan como elementos de retroalimentación necesarios.

Este festival se realiza al sur de Francia, esta ciudad es considerada como el principal núcleo poblacional del departamento de Vaucluse y destino turístico (Sanchez, 2008). El Festival de Aviñón, fue fundado en 1947, cuando Jean Villar organiza una semana de arte en Avigñon y que para el siguiente año cobraría con el nombre de festival de Avigñon el cual es una de las más importantes manifestaciones internacionales del espectáculo contemporáneo en vivo. 


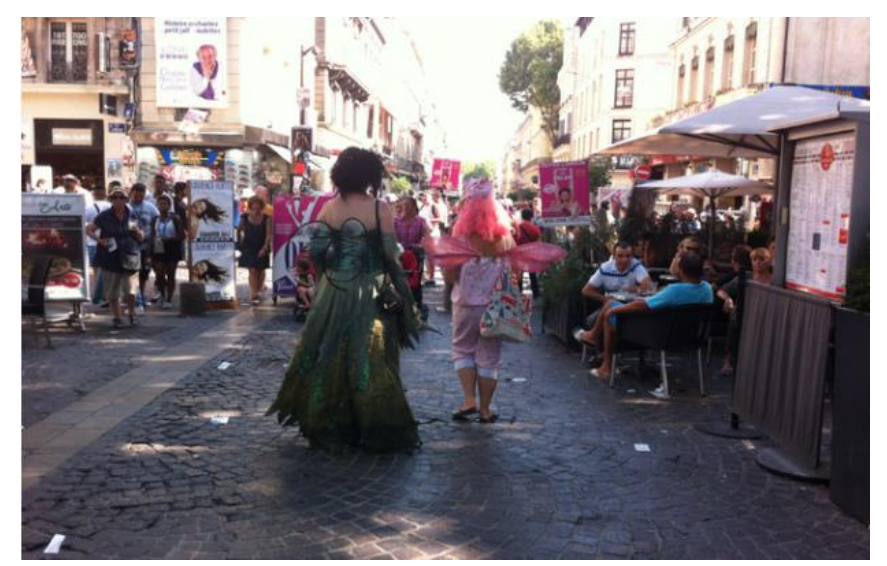

Ilustración 5. La plaza de L'horloge popular entre los asistentes al festival de Avigñon Fuente: Alice Dubois

Se realiza en el mes de Julio de cada año, bajo el calor, la brisa y la pausa de Mediterráneo, Avigñon se convierte en una ciudad-teatro, transformando su patrimonio arquitectónico en diversos lugares de representación, majestuosos o sorprendentes, que acogen a decenas de miles de amantes del teatro de todas las generaciones (Sanchez, 2008). También se celebra en el famoso festival de Aviñón el "In y Off, una de las grandes citas del espectáculo contemporáneo. El festival In, que se desarrolla el patio de honor del palacio de los Papas, está dedicado a las representaciones teatrales, los conciertos o la danza. El festival Off ofrece un gran número de espectáculos por toda la ciudad (France-Voyage.com, 2016).

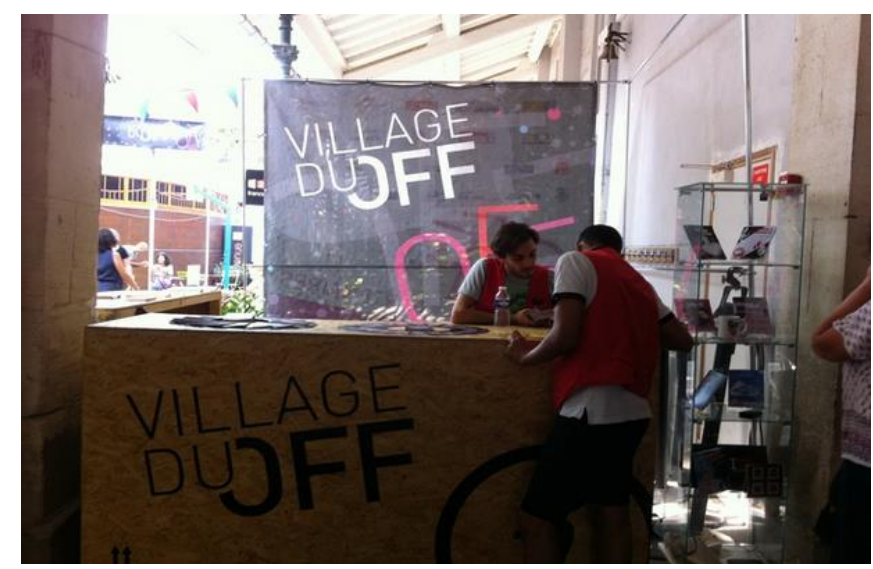

Ilustración 6. La Villa de OFF escuelas ambulantes Fuente: Alice Dubois

Muchos de los espectadores vienen de diferentes lugares y pasan unos días de vacaciones en Avigñon, asistiendo a algunas de las 40 obras de teatro, espectáculos de danza, artes plásticas o música. El festival logra la unión asombrosa de un público popular con la creación internacional, Avigñon, la ciudad es un foro al aire libre, en donde los asistentes al festival hablan de los espectáculos y comparten sus experiencias de los espectadores. A lo largo de un mes, todo el mundo tiene acceso a una cultura contemporánea y en vivo. 


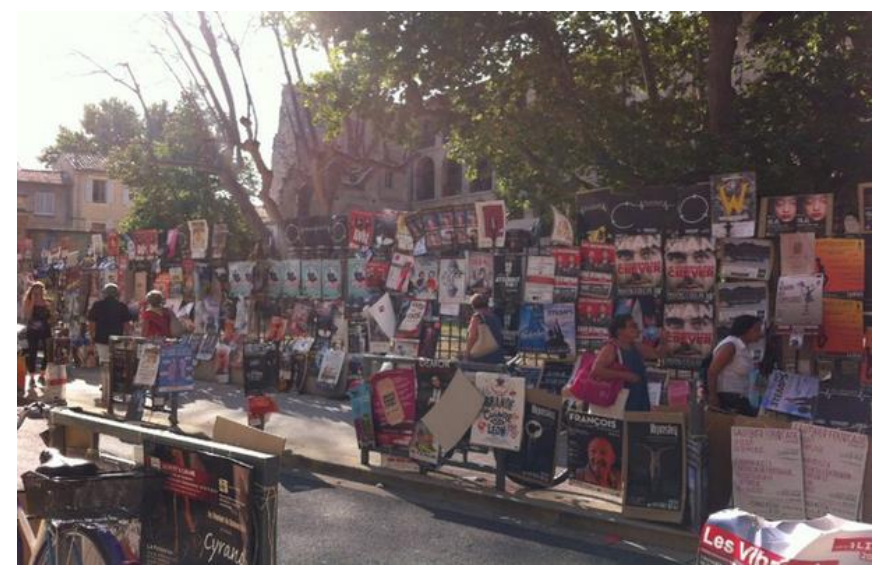

Ilustración 7. La bataille de l'affichage - la calle de las cuerdas

Fuente: Alice Dubois

Cada edición del festival de Avigñon es concebida con la colaboración de un artista asociado para crear el mapa de un territorio artístico. Por encima de las propias creaciones, la programación entera se inspira libremente en sus problemáticas, prácticas y pasiones. El programa elaborado está compuesto por una treintena de equipos artísticos, cuya obra puede exhibirse durante el tiempo que dura el Festival, con uno o varios espectáculos, pero que también puede ser objeto de lecturas, exposiciones, películas, debates, elementos que permiten entrar en el mundo de estos artistas. (Sanchez, 2008)

Al realizar una visión más pragmática, con la intencionalidad referida a encontrar los puntos destacados pero también las falencias de este festival, tomado como referencia para la implementación del festival de Loja, podemos destacar algunas percepciones.

En primera instancia se trata de un festival "selecto", en que sólo cuarenta espectáculos engrosan una lista de eventos bien confeccionada, con una fuerte representación internacional y un impresionante despliegue de medios en las producciones. A la impecabilidad de los montajes se añade la grandiosidad de los espacios de representación, muy en la tónica del festival de Avigñon, Patrimonio de la Humanidad.

El Festival se financia en un 60 por ciento a través de subvenciones públicas de los diferentes organismos que lo patrocinan, más un 35 por ciento que se obtiene gracias a la venta de entradas, quedando un resto marginal de aproximadamente un 5 por ciento, que proviene de la financiación privada y del remanente del propio Festival. Lo cierto, sin embargo, es que se trata de un Festival de y para franceses. Una mayoría aplastante del público asistente es francés, frente a la internacionalidad de otros festivales; a pesar de que muchos de los espectáculos sean en inglés u otras lenguas, lo cierto es que no se trata de un festival con una proyección de público muy internacional, como cabría esperar.

\section{Características a mejorar:}

El público estándar de este tipo de programas, fuera de los programas-taller que se ofrecen para jóvenes, es el de matrimonios franceses más allá de la cincuentena. Que no espere, pues, el potencial asistente al Festival encontrar jóvenes de todos los países, como sucede en la 
mayoría de los festivales, sino un público francés de un estrato social y cultural muy determinado. (Sánchez, D. S. , 2008).

La demanda del público, actores y directores de los espectáculos, en parte por el éxito que exigía contar con más espacios. Escaso dominio del idioma en la que se presenta cada una de las obras y eventos dentro del mismo. No realizar presentaciones escénicas para cada generación. Se sigue correspondiendo en la actualidad con el deseo de su fundador: ser un «teatro de vocación ciudadana» que lastimosamente hasta el momento no lo es para ninguno de los ciudadanos del lugar. (Antiguo miembro de Vooruit)

\section{Características que se pueden tranferir}

- El Teatro Moderno que es el lugar de representación para el arte, debe estar adecuado para todos los tipos de arte a representar (danza, artes plásticas, música, etc.) y para la cantidad de gente que va acudir.

- Hacer de este Festival un punto de encuentro de artistas, profesionales del arte, turistas, espectadores y ciudadanía en general.

- Planificar una parrilla de representaciones escénicas para cada generación, con horarios específicos,

- Que en cada versión se logre presentar algo nuevo, creado por la ciudad con su identidad, programas que como en Avigñon estimulen a las personas a regresar a ver nuestro arte.

Finalmente, se puede considerar un referente más cercano a la idiosincrasia propia vinculada a la academia y a la cultura, es el caso del Festival de Teatro de Manizales, pues en Latinoamérica esta ciudad fue la única que se atrevió a abrirle las puertas al Movimiento Teatral Universitario por una razón muy sólida, la ciudad tiene una fuerte vocación universitaria. Fue así como en 1968 la ciudad de Manizales se convirtió en la anfitriona del Festival de Teatro Universitario. A partir de 1968 la ciudad se constituyó como la única sede oficial del Festival de Teatro Universitario en Colombia, es decir, lo que fue el inicio para el actual Festival de Teatro de Manizales, por él han pasado 1500 grupos teatrales de 40 países.” (Morales, O. R. C., 2011)

\section{Conclusiones y recomendaciones}

Se ha dado a conocer las debilidades y fortalezas que tiene Loja en el ámbito cultural al ser una urbe tradicionalmente cultural y musical que posee este potencial que se pondrá precisamente en escena, en el primer festival internacional de artes vivas, en cuyo caso hemos descrito algunas precisiones en lo referente al manejo urbano y ciudadano del concepto de producto cultural, para cuyo efecto la referencia de eventos similares planteados, plantea algunos retos y genera también algunas precauciones a aplicar en un esfuerzo de sostenibilidad.

Este documento preparado en las aulas universitarias, tiene como objeto aportar algunas visiones favorables a la implementación de un producto cultural que finalmente genere desarrollo para la provincia de Loja, en este caso creemos adecuado transcribir las sugerencias finales del grupo de estudiantes de la escuela de arquitectura de la Universidad Internacional del Ecuador, afincada en Loja (UIDE Loja) en un grupo focal de opinión realizado medio año antes de la presentación del presente artículo: 
Se recomienda crear atractivos simples pero que hagan destacar el arte de la calle en especial ya que en la ciudad destacan mucho los juglares, estos se los puede ver en las diferentes avenidas de la ciudad, el arte callejero es más destacado en estos días, se debería brindar un espacio para su desarrollo y crecimiento no solo personal sino de la ciudad.

Es importante la utilización de las instalaciones del antiguo colegio Bernardo Valdivieso, con el fin de integrar la plaza de la cultura (planteada), y el tradicional teatro Bolívar, para el desarrollo de los eventos del festival.

Potenciar la reutilización de tributos e impuestos que se generen en la ciudad, en actividades relacionadas, con el objeto de contar con fondos que sirvan de base para mantener la actividad entre la realización de cada festival.

Incentivar la práctica de las disciplinas escenográficas, especialmente el teatro con el objeto de conseguir un nivel adecuado a los grupos artísticos que postulan y asisten a la cita del festival.

Sumergir a la ciudad en las artes, en el lapso de tiempo en el cual se desarrolla el festival, incluyendo todo tipo de atractivos en los cuales también participen los barrios periféricos y las parroquias rurales del cantón.

La cultura como dinamizador de desarrollo es un concepto que posicionará a Loja entre las primeras ciudades ecuatorianas en rescatar la cultura local, y reeditar su membrete "Loja capital musical", deberá vivenciarse con el turismo generador de desarrollo ambientalmente amigable, generadora de talento.

Proteger este legado para generaciones futuras y la responsabilidad de asumir y potenciar las características históricas de Loja.

Es necesario, entrelazar una red de los espacios públicos ya existentes en Loja, los cuales se adaptarían de manera efímera como "plazas - pabellones culturales" que albergarían el festival en off de Loja con variada programación al aire libre. Dichos itinerarios y recorridos deben ser con atractivos heterogéneos para integrar a personas de diversas edades.

Promover un posicionamiento de la fecha de desarrollo del festival de Loja, en el calendario mundial de teatro, las artes escénicas y las artes vivas, con una marca ciudad-cultural.

Las artes escénicas y especialmente el teatro pueden introducirse en Loja como carreras profesionalizantes, tecnologías afines, diplomados específicos en disciplinas artísticas participantes, para lo cual se requiere un impulso a la academia a través de las universidades locales o de aliados externos.

Estudiar la pertinencia de hacer el "festival en off" en el centro histórico por la aglomeración colapso en vías que actualmente se están interviniendo en el proyecto de regeneración urbana que lleva adelante el municipio del cantón. 
Generar un circuito o clúster especializado de tipo regional, nacional y transfronterizo con el norte del Perú.

Analizar la permanencia y relación al evento de manera continua de los "jueves culturales" (evento producido por la alcaldía de Loja, ya tradicional), considerando como temporalidad importante su existencia y ampliación.

Desarrollo de capacidades locales en infraestructura de apoyo, de más fácil especialización como tramoyistas, maquilladores, escenografía, artesanías conmemorativas, etc.

Fomentar la interculturalidad e integración cultural de manera más cosmopolita.

\section{Agradecimientos}

Estudiantes de la Universidad Internacional del Ecuador, extensión de Loja, en la Escuela de Arquitectura: Abad Muñoz Jhinsson Javier, Bravo Valarezo Luis David, Cevallos Sigcho Jefferson Leonardo, Cango Armijos Janneth Ximena, Chamba Llivigañay Verónica Valeria, Ludeña Sarango Geovany Patricio, Montoya Vallejo Romina Lisseth, Picoita Rengel José Luis, Solórzano Cabrera Gabriela Yamilex, Santos Jaramillo Pablo Javier, Salinas Quezada Dennis Angel, Valarezo Ramírez Arianna Stefania, Vivanco Jiménez María Alejandra. Ministerio de Cultura del Ecuador, sede provincial de Loja.

\section{Bibliogrfía}

Antiguo miembro de Vooruit, B. (s.f.). Libro Movilidad. Obtenido de Coproducciones y Giras Internacionales: http://on-the-move.org/files/news/MovilidadChapter1Coproductions.pdf

Asuaga, C. L. (2005). Las artes escénicas y la teoría general del costo.

Casto, S. Â. (2002). El nuevo papel de la cultura en la definición de objetivos y estrategias en las ciudades. Periférica. Revista para el análisis de la cultura y el territorio, 1(3), 207-212.

Comunicación, S. S. (23 de 01 de 2015). Noticiero ciudadano. Obtenido de El ciudadano: http://www.elciudadano.gob.ec/loja-acogera-desde-2016-al-festival-internacional-deteatro/

De Elizagarate, V. (2003). Marketing de ciudades. Pirámide.

Eloísa Jaramillo, S. J. (2012). Artes Vivas Colombia. Colombia.

Espinoza., L. B. (2012). Identificación Y Dinamización Del Corredor Turístico Cultura Y Tradición, Sector Loja. Recuperado El 05 De 01 De 2016, De Identificación Y Dinamización Del Corredor Turístico Cultura Y Tradición, Sector Loja.: http://dspace.unl.edu.ec/jspui/handle/123456789/984 
Flores Ruiz, D. (2015). Turismo cinematográfico y desarrollo económico local: el Festival de Cine de Huelva.

France-Voyage. (2016). France-Voyage.com. Obtenido de Avignon: http://www.francevoyage.com/francia-ciudades/avignon-commune-33652.htm

France-Voyage.com. (2016). Obtenido de France-Voyage.com: http://www.francevoyage.com/francia-guia-turismo/avignon-794.htm

Ignacio Amate Fortes, A. G. (2011). Factores determinantes del desarrollo economico y social. Recuperado el 05 de 02 de 2016, de Factores determinantes del desarrollo economico y social: https://www.unicaja.es/resources/1319798719449.pdf

Morales, O. R. C. (2011). Festival de Teatro de Manizales, el decano de las artes escénicas.

Pose, H. M., (2008) Ciudad Y Acción Cultural: Acercamiento A Un Quehacer Cívico-Social.

Sanchez, D. S. (11 de 06 de 2008). El Festival De Teatro De Avignon. Obtenido de Esticomitia: http://parnaseo.uv.es/Ars/Esticomitia/Numero6/avignon.pdf

Tandil, N. (s.f.). XXVII Congreso Argentino De Profesores Universitarios De Costos 